\title{
Background on FOMC Meeting Minutes
}

Deborah J. Danker and Matthew M. Luecke, of the Board's Division of Monetary Affairs, prepared this article.

On December 14, 2004, the Federal Open Market Committee (FOMC) decided to move up the publication of its minutes to three weeks after the end of each meeting. That action has cut in half the average time between the meeting and publication of the minutes. It has also apparently heightened public attention to the FOMC minutes. To give additional context to the Committee's decision, this article outlines previous changes to the release schedule for the minutes and provides a brief overview of the content of the minutes and the way they are now produced.

From the inception of the FOMC, the Federal Reserve has had an obligation to maintain records of the Committee's policymaking actions and to publish those records in its annual report to the Congress. ${ }^{1}$ Accordingly, the Federal Reserve initially published a summary of FOMC proceedings once a year. Over time, however, as views about public access to information changed and as financial markets matured, broadened, and deepened, the FOMC provided more information more promptly, going well beyond the basic information required by the Federal Reserve Act.

This article focuses on the minutes and their production, but the minutes are by no means the sole source of public information about FOMC policymaking. For example, the Committee releases a statement on the same day that policy decisions are made, the Chairman provides semiannual testimony to the Congress, and the Board submits semiannual Monetary Policy Reports, which include a summary of the economic projections of the Board members and

\footnotetext{
NotE. The authors are grateful for helpful comments received, especially from their former colleagues Normand Bernard and David Lindsey.

1. Section 10 , paragraph 10 of the Federal Reserve Act states: "The Board of Governors of the Federal Reserve System shall keep a complete record of the action taken by the Board and by the Federal Open Market Committee upon all questions of policy relating to open-market operations and shall record therein the votes taken in connection with the determination of open-market policies and the reasons underlying the action of the Board and the Committee in each instance. The Board shall .. . include in its annual report to the Congress . . . a copy of the records required to be kept under the provisions of this paragraph."
}

Reserve Bank presidents. In addition, the Chairman testifies on the economy and other topics on several occasions during the year; Committee members regularly give public speeches; and a wide range of documents, including FOMC meeting transcripts, is made available after a five-year lag.

\section{HISTORY}

The Federal Open Market Committee was created in its modern form by the Banking Act of 1935, and for much of its history, the publicly available reports from its meetings were the "Records of Policy Actions"-also known as the "Policy Record." (See timeline chart of past and present nomenclature.) For its own use, the Committee initially maintained extensive "minutes," which were detailed records of attendance, discussions, and decisions at each meeting. These minutes remained confidential, and the Records of Policy Actions, which were published once a year, were the official statement of FOMC policymaking for decades. ${ }^{2}$ At first, the Records of Policy Actions included only a paragraph or two of background or reasoning behind each action. However, these records grew over time and had reached an average of about five pages per meeting by the mid-1960s, when the Committee reviewed its information-disclosure practices.

\section{7-Release of Record of Policy Actions after Ninety Days}

In discussions undertaken in light of the pending effective date of the Freedom of Information Act, the Committee agreed that information about monetary policy decisions should be made available to the public on a timely basis but that caution was needed so that the information released would not impair the Committee's ability to formulate and implement policy. The consensus that emerged was that the time lag on the release of information should be shortened.

Accordingly, in June 1967, the Committee announced that it would release the Record of Policy Actions about ninety days after each meeting and

2. In 1964, the FOMC made the minutes for the years 1936-60 available to the public through the National Archives. 


\section{Reports from FOMC Meetings: Past and Present Nomenclature}

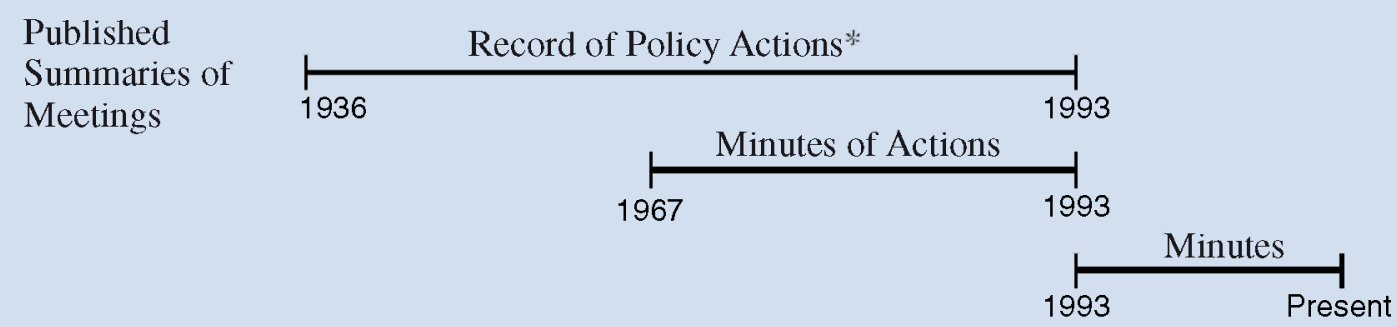

Detailed Internal Accounts of Meetings

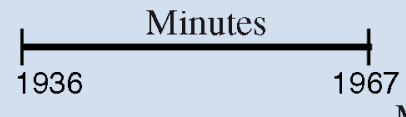

1967
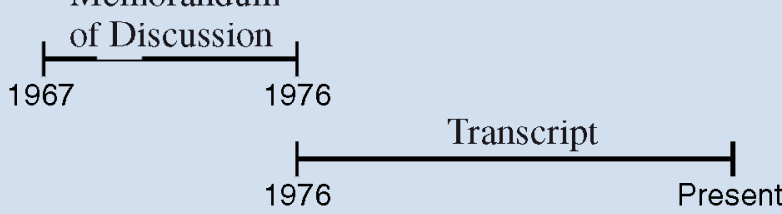

*Also referred to as "Policy Record."

would also publish it in the Federal Reserve Bulletin. The Committee believed that a ninety-day lag would be a relatively safe starting point and that, as experience was gained, it might be possible to reduce the lag between policy action and publication.

The Committee also began to make available on the same schedule a new document-a companion piece to the Record of Policy Actions-that was called "Minutes of Actions." This document included summaries of all actions (both policy actions and nonpolicy actions, such as procedural or organizational votes) as well as a list of attendees. The document did not state the reasoning behind the actions or give any indication of the discussion at the meeting; that information was covered in the Record of Policy Actions. The material previously included in the FOMC's internal minutes was now in effect split into two documents - the Minutes of Actions and the "Memorandum of Discussion," a detailed account of the discussion at each meeting. Subsequently, the Committee began releasing its internal minutes, and later the Memorandum of Discussion, to the public with a lag of about five years. ${ }^{3}$

3. In 1967, the Committee sent the internal minutes for 1961 to the National Archives. In 1970, it transmitted those for 1962-65 and decided on a regular schedule of releasing them after about five years.

\section{5-Release of Record of Policy Actions} after Forty-Five Days

In the years after the passage of the Freedom of Information Act, it became clear that there was a substantial public appetite for further and moretimely information related to the Committee's meetings. Committee discussions about the schedule and content of existing information releases resulted in a decision to cut the lag on the release of the Record of Policy Actions from ninety days to forty-five days. The March 1975 announcement about shortening the release lag time noted that "in the light of experience, the Committee decided that a delay as long as 90 days was no longer necessary to avoid an unacceptable degree of risk that speculators would be able to take unfair advantage of the information or that market reactions would impair the effectiveness of the Committee's functions."

\section{6-Earlier Release of Lengthened Record of Policy Actions}

In May 1976, the Committee announced that an expanded version of the Record of Policy Actions for each meeting would be released a few days after the 
subsequent meeting. ${ }^{4}$ Because the Committee was meeting monthly at that point, the lag shortened to an average of just over thirty days. ${ }^{5}$ The expanded document, which was approximately doubled in length, included a fuller discussion of economic and financial developments and more information on members' views on current and longer-run policy issues. At the same time, the Committee decided that continued production of the Memorandum of Discussion was no longer merited.

\section{3-Combination of the Record of Policy Actions and Minutes of Actions}

Congressional interest in FOMC information disclosure picked up substantially in the early 1990s. To dispel some confusion that arose in the midst of discussions with the Congress about information release and to simplify its procedures, the Committee decided to combine the content of the Record of Policy Actions and that of the Minutes of Action into a single document called the "Minutes of the FOMC Meeting." Also, the Committee agreed to construct lightly edited transcripts of its previous meetings from unedited transcripts dating back to 1976, which would be released to the public with a lag of about five years. ${ }^{6}$ In early 1995, the Committee decided to follow the same publication practice for future transcripts as well.

\section{4-Release of the Minutes after. Three Weeks}

In December 2004, the Committee announced that it would expedite the release of the minutes of its meetings to three weeks after each meeting, a reduction of between two and five weeks in the lag (the previous release schedule had depended on the timing of the subsequent meeting, which could vary by several weeks). In support of this decision, participants at that FOMC meeting noted that the minutes contained a more complete and more nuanced expla-

4. In practice, this decision meant that the minutes were released on the Friday after the next meeting. They continued to be released on that schedule until early 1997 , when the release was shifted to the Thursday after the next meeting.

5. In 1981, when the FOMC cut its meeting schedule back to eight regularly scheduled meetings each year, the lag on releasing the policy record lengthened concomitantly: "A few days after the subsequent meeting" came to mean a publication date that was once again about forty-five days, on average, after the meeting.

6. To date, transcripts for 1979-99 have been released; 1976-78 are pending. nation of the reasons for the Committee's decisions and views of the risks to the outlook than was possible to include in the post-meeting announcement. They also noted that the earlier release would help markets interpret economic developments and predict the course of interest rates and that the minutes would provide a more up-to-date context for public remarks by individual policymakers. Some concern was expressed, however, that the financial markets could misinterpret the minutes and that the specter of early release could either impair the discussion at FOMC meetings or lead to less-comprehensive, and therefore less-useful, minutes over time. On balance, the Committee viewed the pluses as outweighing the minuses and decided unanimously to expedite the release of the minutes.

\section{CONTENT}

The FOMC expressed its views on the content of the minutes years ago when it said that the document "contains a full and accurate report of all matters of policy discussed and views presented, clearly sets forth all policy actions taken by the FOMC and the reasons therefor, and includes the votes by individual members on each policy action." 7 In practice, this means that the minutes cover all policy-related topics that receive a significant amount of attention at the meeting and they record the policy decisions and the reasoning supporting those decisions. All policy votes are recorded. If there is a dissent, the reason for the dissent as expressed at the meeting is included in the minutes. All attendees at the meeting are named and identified by title and affiliation. Because the objective of the minutes is to provide a fair, accurate, and complete record of the FOMC meeting, only information that was available at the time of the meeting is reflected in the content of the minutes, and only opinions that were expressed at the meeting are included. Subsequent information-such as a market reaction to the post-meeting statement, new economic data, or any notation votes or unscheduled FOMC meetings that might occur before the publication date of the minutes-would not be included in the minutes for that meeting; it would be reflected in the minutes of the next regularly scheduled meeting.

7. From the March 10, 1977, FOMC - Statements of Policy, which is available in the Federal Reserve Regulatory Service, vol. 4, loc. no. 8-830. That statement referred specifically to the Record of Policy Actions, which at the time was the functional equivalent of the current minutes. 


\section{Conventions of Language}

The minutes try to convey clearly the content of the meeting through commonly used language. At times, the minutes use specific terms in the interest of precision. For example, the minutes distinguish among the terms "members," "meeting participants," and "staff." "Members" refers only to the twelve members of the FOMC-namely, the individuals eligible to vote at that meeting-whereas "meeting participants" includes both the members and the seven nonvoting Reserve Bank presidents (or those attending in their stead). The views of all meeting participants are included in the discussion of current economic conditions and the outlook. When it comes to the description of the policy discussion (usually the final few paragraphs of the minutes), however, the views of the twelve members are the focus. This focus reflects the intention of this section, which is to provide the specific reasons underlying the policy action decided upon by those voting at the meeting. Comments by other meeting participants may be mentioned by way of background in this section when it is felt that they provide important context for the policy discussion, but such comments would not be attributed to members.

To give an indication of how widely expressed a particular view is at a meeting, the minutes use common quantitative wording: "all," "most," "many," "several," "few," or "one," in descending order. Often, other similar words are used for stylistic purposes, and care should be used by readers to avoid over-interpreting specific wording. Moreover, tracking expressions of support for particular viewpoints in the give-and-take of a meeting tends to be an imprecise science. For example, a meeting participant speaking relatively late in a meeting may choose not to repeat views expressed earlier by others, or speakers may alter or amend their views in the course of the meeting. Therefore, these quantitative words should be read as indicative rather than definitive.

\section{Document Structure}

The minutes follow a structure that is fairly consistent from one meeting to the next. The initial section includes a list of attendees and any noteworthy organizational or procedural items. For the FOMC's annual organizational meeting, this initial section is appreciably longer because it also includes the election of Committee officers and the approval of various Committee documents.

The second section of the minutes follows a moreor-less standard format in presenting an overview of the economic and financial information provided to the Committee. This section ends with a summary of the staff forecast at the time of the meeting. In the case of the two-day meetings, during which the Committee discusses a special topic, the opening paragraphs of this section typically summarize the staff presentation and the Committee discussion of the special topic.

The third section covers meeting participants' perspectives on current economic developments and the outlook. The structure of this section is less standard because it depends upon the focus of the discussion. Nevertheless, the section typically includes paragraphs on such topics as business investment, consumer spending, the labor market, the external sector, and inflation. For the two-day meetings, the third section tends to be longer, in part because the minutes cover participants' projections for the economy.

The fourth section of the minutes focuses directly on the policy decision. It includes a few paragraphs covering members' views on policy and any discussion of the post-meeting statement. It also records the vote, including the language that the Committee voted on and the vote of each member by name. The minutes then conclude with confirmation of the date for the FOMC's next scheduled meeting.

$A$ record of any notation votes that occurred during the period between regularly scheduled meetings would be included at the end of the minutes of the later meeting, as would the minutes of any unscheduled FOMC meetings, such as conference calls, that occurred during that period.

\section{PROCESS}

The minutes of each FOMC meeting are now prepared on an accelerated timetable in order for the document to be approved by the Committee and published on time, twenty-one days after the end of the meeting. An internal experiment covering most of the 2004 FOMC meetings preceded the decision to expedite the release, and that experiment was an essential element in providing the Committee with the necessary confidence that the shortened schedule could be met reliably.

\section{Staff Draft}

The minutes are drafted by staff members of the Board of Governors who attend the FOMC meeting. But the process of producing the minutes begins even before the meeting, as the standard staff summaries of the economic and financial situation (for example, 
the Greenbook and the Bluebook) prepared for each meeting become available a few days ahead of the meeting. A Board staff member uses those summaries, along with the staff presentations prepared for the FOMC meeting and other input, to draft the section of the minutes that reviews the information provided to the Committee. Shortly after the meeting, a draft of this section is completed, and several senior staff members review it for accuracy and pass it on to be incorporated with the other sections.

The writing of the third and fourth sections of the minutes, which cover the discussion of the economic outlook and the policy decision, begins as soon as the meeting ends. Several senior staff members gather and discuss major themes from the meeting and the way they will be covered in the minutes. The author of these sections, an officer from the Board's Division of Monetary Affairs serving on a rotating basis, begins a draft based initially on notes taken at the meeting. By the day after the meeting, however, a rough transcript of the meeting has been prepared, and the author typically relies on the transcript to complete the draft. By the end of the week of the meeting, a draft that includes all sections of the minutes is circulated among the officers in the Division of Monetary Affairs for review.

\section{Policymaker Review}

A series of several rounds of policymaker review of the draft minutes begins during the week after the meeting. After the minutes have been reviewed by the Chairman, the Secretary of the FOMC sends the draft to the meeting participants for comments late in the week after the FOMC meeting (typically on Thursday of that week, or nine days after a Tuesday meeting). Early in the subsequent week, the Secretary sends out a revised draft that incorporates input received from meeting participants. By the end of the second week after the meeting, a final version is produced and provided to the Committee for approval by a notation vote. The notation voting period lasts about four calendar days and closes at noon on the day before publication. After the processes of preparation and coordination for the release of the minutes are completed, the approved minutes are published at 2:00 p.m., twenty-one days after the policy decision was made.

This shortened schedule for release has required the Federal Reserve to devote additional resources to produce the minutes. A wider circle of drafters is engaged to ensure that the deadline is met, and logistics are closely coordinated to ensure that policymakers are available for timely review and approval of the minutes. The Committee believed that the costs and risks associated with the new schedule were outweighed by the benefits of additional policy transparency and openness. As such, the earlier release of the minutes was viewed as consistent with the evolution of the FOMC's communication strategy over the years. 